\title{
ESTILOS
}

DOI: https://doi.org/10.11606/issn.1981-1624.v26i3 p536-547.

\section{Artigo \\ Psicose infantil e desejo materno a partir da topologia do nó borromeano}

\author{
Lara Batista Belfi; Ariana Lucero
}

Resumo. Neste artigo, investigaremos o quadro clínico da psicose infantil a partir da proposta de Marie Christine Laznik de abordar as psicopatologias da infância através da topologia do nó borromeano. No caso da psicose infantil, os impasses da formação do sujeito são correspondentes às falhas nos movimentos 2, 3 e 6 da trança, que dariam ao nó borromeano sua consistência em três elos representantes das instâncias Real, Simbólica e Imaginária. Tendo em vista que as movimentações constituintes concernem às interações do Outro primordial - encarnado pelo agente materno - com o sujeito em formação, serão destacadas as questões colocadas à criança que se encaminha para uma possível psicose e a especificidade de sua posição diante do Outro.

Palavras-chave: psicose infantil; constituição do sujeito; função materna; nó borromeano.

\section{Psicosis infantil y deseo maternoa partir de la topología del nodo borromeo}

Resumen. En este artículo investigaremos el cuadro clínico de la psicosis infantil a partir de la propuesta de Marie Christine Laznik para abordar las psicopatologías infantiles a través de la topología del nodo borromeo. En el caso de la psicosis infantil, los impasses de la formación del sujeto son tratados como fallos en los movimientos 2, 3 y 6 de la trenza, que darían consistencia al nodo borromeo en tres eslabones que representan las instancias Real, Simbólica y Imaginaria. Teniendo en cuenta que los movimientos constituyentes conciernen a las interacciones del Otro primordial - encarnado por el agente materno - y el sujeto en formación, se resaltarán las preguntas planteadas al niño que se encamina a una posible psicosis y la especificidad de su posición ante el Otro.

Palabras clave: psicosis infantil; constitución del sujeto; función materna; nodo borromeo.

\section{Childhood psychosis and maternal desire from the borromean knot topology}

Abstract. In this article we will investigate the childhood psychosis based on the psychoanalyst Laznik proposal to address childhood psychopathologies through the topology of the borromean knot. In the case of childhood psychosis, the impasses in the formation of the subject correspond to the failures in movements 2, 3 and 6 of the braid that would give the Borromean knot its consistency in three links representing the Real, Symbolic and Imaginary. Bearing in mind that the constituent movements concern the interactions of the primordial Other -

*Psicóloga e psicanalista. Integrante do Projeto de Pesquisa "A clínica psicanalítica da criança aos bebês: entre o cuidado e a patologização da infância” na Universidade Federal do Espírito Santo, Vitória, ES. Email: larabelfi@gmail.com

**Professora Adjunta da Universidade Federal do Espírito Santo, Vitória, ES, E-mail: ariana.lucero@ufes.br 
incarnated by the maternal agent - and the subject in training, the questions raised to the child who is heading for a possible psychosis and the specificity of his position before the Other will be highlighted.

Keywords: childhood psychosis; constitution of the subject; maternal function; borromean knot.

\section{Psychose infantile et désir maternel à partir de la topologie du noeudborroméen}

Résumé. Dans cet article, nous étudierons la psychose infantile à partir de la proposition de la psychanalyste Laznik d'aborder les psychopathologies de l'enfance à travers la topologie du nœud borroméen. Dans le cas de la psychose infantile, les impasses de la formation du sujet correspondent aux échecs des mouvements 2, 3 et 6 de la tresse qui donneraient au noeud borroméen sa cohérence dans trois liens représentant les instances réelles, symboliques et imaginaires. Considérant que les mouvements constitutifs concernent les interactions de l'Autre primordial - incarnée par l'agent maternel - avec le sujet en formation, les questions posées à l'enfant qui se dirige vers une possible psychose et la spécificité de sa position devant l'Autre seront mises en évidence.

Mots-clés: psychose infantile; constitution du sujet; fonction maternelle; nœud borroméen.

A predominância do discurso médico-científico sobre as psicopatologias infantis vem proporcionando a proliferação de modelos diagnósticos que buscam abranger cada vez mais variantes de comportamento. Atualmente, crianças que apresentam questões psíquicas graves são majoritariamente inclusas na categoria do autismo, enquanto a categoria de psicose infantil vem desaparecendo dos manuais psiquiátricos (Bernardino, 2010). A psicanálise, por questionar a primazia da organicidade, sustenta o diagnóstico diferencial da infância a partir da posição do sujeito diante da linguagem. A simples omissão das psicoses infantis dos manuais psiquiátricos nos transtornos diagnosticados na infância (APA, 2002) ou nos transtornos do neurodesenvolvimento (APA, 2014) não significa que esse quadro clínico deixou de existir do ponto de vista psicanalítico (Bernardino, 2010). Por isso, cabe, sobretudo, resgatar as especificidades do quadro clínico da psicose infantil.

\section{Linguagem e topologia}

Lacan (1960-1964/1998), ao conceber a estrutura do inconsciente como linguagem, coloca a noção de sujeito dependente do Outro - "lugar onde se situa a cadeia significante" (Lacan, 1964/2008, p. 200) - no cerne de sua reelaboração da teoria freudiana. Disso depreende-se que o sujeito não nasce pronto: é produto da relação entre o organismo e o mundo simbólico que está estabelecido previamente. A linguagem, ao preceder a existência do ser vivo, configura-se como um ponto de encontro inevitável para o recém-nascido. Ao entrar no mundo, a criança esbarra com designações que lhe eram anteriores e, ao lidar com elas, precipita-se como sujeito. A clínica psicanalítica com crianças, portanto, é possível ao considerarmos o tempo da infância como o tempo de formação do sujeito. Perseguir a via de que as operações necessárias à estruturação do sujeito efetuam-se pela linguagem distingue-se de uma perspectiva médica de maturação progressiva e dá vigência à afirmação freudiana de que a infância é imperecível (Vorcaro, 1999). Justamente por tratar-se do tempo de inscrição da linguagem, as articulações constituintes ainda estão por se estabelecer efetivamente, e, por isso, os diagnósticos psicanalíticos na infância são tomados como não-decididos. O diagnóstico em psicanálise, portanto, tem função de indicar a posição que a criança assume diante do Outro ao constituirse como sujeito e, assim, direciona o caminho de tratamento que o psicanalista deve tomar para dar condições ao sujeito de lidar com a linguagem. Lacan (1974-1975), ao formalizar a situação 
do ser falante em relação às dimensões Real, Simbólica e Imaginária que constituem o psiquismo, se utiliza da topologia do nó borromeano, que consiste em três elos entrelaçados de forma que, se algum deles se solta, os outros dois também se desconectam.

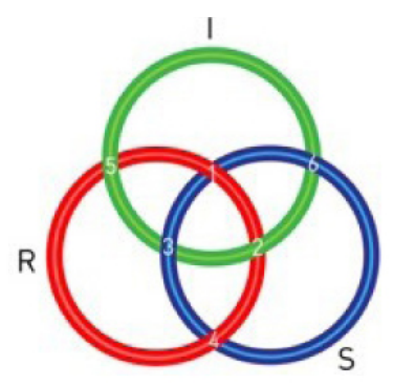

Figura 1. Nó Borromeano.

Fonte: Capanema e Vorcaro, 2017.

Esta topologia permitiu que Vorcaro (2004) desenvolvesse a trajetória da trança, que considera que o enlace do nó borromeano decorre de seis sobreposições intercaladas entre Real, Simbólico e Imaginário, em que cada um desses seis movimentos representa ações constituintes efetuadas através do Outro primordial. Laznik (2016) toma o trabalho de Vorcaro (2004) para pensar a situação das crianças que se encontram com dificuldades de emergir como sujeito falante. Para Laznik (2016), as dificuldades das crianças autistas e psicóticas com a linguagem podem ser discernidas por impasses que se localizam em diferentes momentos do tempo lógico constitutivo, isto é, em diferentes movimentos da trança. A autora constata que, em uma resolução psicopatológica, pelo menos três dos movimentos da trança poderão se dar de maneira diferente daquele que resulta no nó borromeano e terão efeitos observáveis na criança. Assim, o autismo corresponderia às falhas nos movimentos 1,2 e 5, enquanto a psicose infantil, que será abordada neste artigo, corresponderia a falhas nos movimentos 2, 3 e 6 do trançamento.

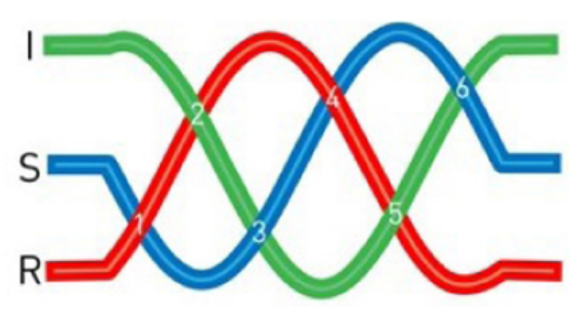

Figura 2. Seis movimentos da trança. Fonte: Capanema e Vorcaro, 2017.

Tendo em vista que as trançagens 2 e 3 representam as ações constitutivas, realizadas pelo agente da função materna, de proporcionar e cessar o momento fálico da criança (Vorcaro, 2004), trata-se de uma investigação sobre a relação que o primeiro representante do Outro pode ter com as dificuldades colocadas à criança dita psicótica, alinhando-se com a perspectiva de que traçar o percurso do sujeito depende da alteridade. Ademais, interrogamos como o sexto movimento da trança pode ter incidência retroativa sobre os primeiros tempos, já que ele representa o que é fundamentalmente falho pela definição lacaniana das psicoses (Lacan, 19551956/1988). 


\section{Psicose e castração simbólica}

Importante ressaltar que o tempo imperfeito implicado nas ações constitutivas do sujeito faz com que os movimentos posterior e anterior da trança se articulem simultaneamente, fazendose interdependentes (Vorcaro, 2004). Além disso, o caráter retroativo da formação inconsciente implica que a última articulação constituinte efetive a primeira, mesmo que, na infância, os seis movimentos se sucedam incessantemente até que haja uma resolução posteriormente (Laznik, 2016). Desse modo, cabe inicialmente verificar como o erro no sexto e último movimento da trança incide retroativamente nos movimentos 2 e 3. Para Vorcaro (2004), no encaminhamento típico do sujeito, o sexto movimento da trança - o Simbólico sobre o Imaginário - efetiva o funcionamento desejante: as tentativas do sujeito de ser o objeto de desejo do agente materno, isto é, de corresponder imaginariamente ao falo materno, não são suficientes, pois esse desejo nunca é satisfeito completamente. Por não ser capaz de oferecer ao agente materno aquilo que ele deseja, o sujeito supõe uma presença terceira que poderia fazê-lo. É esse terceiro elemento que interdita a suposta correspondência ao falo materno e efetua a castração simbólica. A representação do falo, como significante da falta, ao ser apreendida em um lugar exterior à mãe e à criança, provoca o sujeito a desejar no lugar em que é suposto, fazendo-o de unidade de medida dos objetos de desejo, isto é, condicionando-o no campo do desejo (Vorcaro, 2004). Assim, o último movimento torna a falta um significante organizador da relação desejante, fazendo do Outro o lugar simbólico a que a criança e o agente materno estão submetidos: a castração simbólica une desejo e lei (Vorcaro, 2004).

Lacan (1955-1956/1988), sem se referir à criança, fundamenta a psicose a partir do que denomina de foraclusão (Verwerfung) do significante Nome-do-Pai, que daria efetivação ao falo como significante e promoveria a castração simbólica. Acrescentando a especificidade do tempo da infância, Laznik (2016) indica que na criança psicótica há uma permanente dificuldade na apreensão do falo como significante, o que faz com que o movimento seis da trança seja inconsistente. Pela maleabilidade que está em jogo no tempo da constituição do sujeito, é precipitado afirmar que há foraclusão, pois isso apenas se define pela resolução edípica em meados da adolescência (Vanoli \& Bernardino, 2008). Sendo assim, é possível conceber a dificuldade de simbolização na criança como um impedimento não definitivo da passagem do Simbólico sobre o Imaginário. Podemos pensar que, na criança psicótica, o significante fálico estaria com dificuldades de se inscrever. O próprio Lacan (1955-1956/1988, p. 294) insere essa hipótese: "A noção de Verwerfung indica-lhes que deve haver alguma coisa que falta na relação com o significante na primeira introdução aos significantes fundamentais".

Conforme Vorcaro (2004), podemos pensar que o sujeito não teria condições de apreender um elemento terceiro a que o Outro materno se dirige. A tarefa de veicular o terceiro elemento castrador é do agente materno: "Cabe à mãe ser o agente da castração, introduzindo para a criança um terceiro elemento que interditará essa relação simbiótica, permitindo que a criança se salve da submissão ao Outro e sustente seu próprio desejo" (Vanoli \& Bernardino, 2008). Essa circunstância de submissão representa a impossibilidade de assunção do Outro como lugar simbólico. A impossibilidade de apreender o falo como o significante que representa a falta retroage sobre todas as experiências do sujeito com o Real, fazendo delas apenas disrupções não simbolizadas. Lacan (1955-1956/1988, p. 237) demonstra esse tipo de relação com a falta: "Trata-se de conceber, não imaginar, o que se passa para um sujeito quando a questão vem dali onde não há significante, quando é o buraco, a falta que se faz sentir como tal”. A castração 
simbólica não encontra meios de se colocar, na medida em que criança não consegue apreender o desejo materno como desejo propriamente dito, que inclui a dimensão da falta. De acordo com Calligaris (1989/2013, p. 82): “A falta de referência terceira implica que a defesa do sujeito se sustenta num saber que não está num terceiro intervindo, mas na coisa mesma e na coisa da qual se trata de se defender".

Lacan (1955-1956/1988, p. 154) nos coloca as seguintes questões acerca da psicose na infância:

E sobre essa questão do começo, nós temos que retornar, a saber, o que é o começo de uma psicose? Será que uma psicose tem, como uma neurose, uma pré-história, quer dizer, uma psicose infantil? Não digo que responderemos a essa questão, mas ao menos a colocaremos. Tudo deixa parecer o contrário, que ela não tem... (p. 154 - tradução nossa).

A ausência de uma pré-psicose significa que a psicose do adulto não decorre necessariamente de uma psicose na infância. Segundo Calligaris (1989/2013, p. 73): “O destino de uma criança que chamamos de psicótica é um destino diferente, geralmente, do que será o destino de um psicótico adulto, até o ponto que diria que um dito psicótico adulto, na continuação de sua psicose infantil, não é propriamente um psicótico". Assim, ainda que as psicoses do adulto e da criança expressem um enfrentamento diante da mesma coisa que fracassa, não é possível afirmar que são correspondentes. Investiguemos, agora, as especificidades desse quadro clínico na infância pela retroação do movimento 6 sobre as movimentações 2 e 3 .

\section{Psicose e inundação imaginária}

O movimento 2, correspondente à passagem do Imaginário sobre o Real, é descrito por Laznik (2016) como o investimento libidinal da criança realizado pelo agente materno. Com Vorcaro (2004), compreende-se que para o sujeito que "vai bem" no seguimento de sua constituição, o Real que faz decalagem entre os termos presença-ausência da primeira matriz simbólica torna irrecuperável a vivência de gozo pleno da primeira experiência de satisfação. A superação da impossibilidade de reencontro com o objeto perdido - aquele que supostamente trazia o gozo pleno - exige do Imaginário a recoberta desse Real, efetuando o movimento 2 da trança.

De toda forma, o sujeito inconstituído, diante do Real, busca retornar à alienação simbólica, equivalendo imaginariamente o agente privador do objeto e o corpo do agente materno. Portanto, localizando no agente materno o saber sobre seu gozo (Vorcaro, 2004). À medida em que no agente materno localiza-se apenas uma potência de saber, a falta permanece se insinuando. O Outro, ao fazer da expressão da criança um enigma para o qual ele não tem a resposta correta, supõe um sujeito desejante. Por também portar uma falta, o Outro imaginário não fornece um gozo pleno à criança: os objetos que oferece fazem suplência insuficiente àquele que foi perdido. É em função da apreensão da falta do objeto que o sujeito pode se inserir na cadeia significante: "O efeito dessa impossibilidade de o Outro responder-lhe constitui a natureza do objeto causa de desejo, objeto $a$, um nada escondido, do Outro que não basta, passível de ser preenchido por qualquer objeto tomado na forma de demanda" (Vorcaro, 2004, p. 95).

Se não há objeto que cessa o desejo, a expressão fonatória do bebê se coloca aberta a qualquer significação e pode ascender ao estatuto do apelo (Soler, 2002/2007). Nesse momento, quem sustenta a condição de desejante do sujeito é o Outro materno, que também é desejante: 
a demanda de um é desejo do outro (Vorcaro, 2004). O encontro do sujeito com o que é oferecido pelo Outro permite pressupor o enigma do desejo materno pela questão: "ele me diz isso, mas o que ele quer?" (Lacan, 1964/2008, p. 209). Assim, a aura imaginária de onipotência do Outro funciona como um ponto de identificação para o sujeito no estágio do espelho (Vorcaro, 2004), que, impotente diante do Outro, procura ser algo para recobrir a própria falta; para isso, localiza uma possibilidade de equivalência àquilo que supõe ser o desejo da mãe, precipitando seu eu. O corpo do sujeito e do Outro são revestidos imaginariamente na tentativa de reestabelecer uma suposta completude entre eles. Recobrem-se duas faltas: a do sujeito e a do Outro, já que ambos não possuem a resposta satisfatória ao desejo, o que proporcionaria a operação seguinte da alienação simbólica: a separação simbólica (Lacan, 1964/2008).

Entendemos que Laznik (2016), ao localizar um acidente no movimento 2, supõe que o Real se encontra impossibilitado de ser simbolizado como falta, causando um embaraço no seu próprio recobrimento pelo Imaginário. A incidência do Real proporciona ao pequeno psicótico a simbolização primordial que inclui a dimensão de uma alternância presença-ausência (Soler, 2002/2007). Mas essa organização entre presença e ausência não se complexifica para esses sujeitos, pois a decalagem entre os pares de termos pelo Real não é superada, a ausência não é simbolizada como falta simbólica. Para a criança em vias de se tornar psicótica, o Outro, por estar sem referência à falta simbólica que seria operada pelo movimento 6 , funciona suprimindo o mal-entendido entre a sua manifestação e a interpretação dada a ela, isto é, há a manifestação da criança, mas o Outro lhe devolve uma resposta satisfatória, se fazendo consistente ao se apresentar correspondendo ao sujeito com aquilo que ele carece. A criança, antes mesmo de manifestar-se a favor do objeto de satisfação, encontra-se com algo do agente materno. Estando a dimensão do enigma do desejo excluída, o sujeito não ascende ao estatuto da demanda. $\mathrm{O}$ Outro, ao saturar a manifestação da criança pela resposta que apresenta, mantém o sujeito identificado à situação primeira de alienação em que tudo o que é do sujeito só pode estar no lugar do Outro (Lacan, 1964/2008). O corpo do agente materno, imaginarizado como Outro onipotente, só ganha borda e se diferencia do corpo da criança se a falta permanece se insinuando.

$\mathrm{Na}$ ausência da dimensão da falta, a imaginarização do agente materno vai além no sujeito inconstituído em situação psicótica: o Outro não é apenas potente por poder fornecer - ainda que insatisfatoriamente - a resposta que a criança não possui ao seu próprio desejo, é Absoluto, já que suprime a possibilidade de o sujeito localizar o que deseja aquém do corpo do agente materno. Por não encontrar um ponto de falta em que poderia se alojar, o sujeito está impossibilitado de operar a separação (Vanoli \& Bernardino, 2008). Esse excesso de imaginarização do Outro permite um estágio do espelho peculiar, em que a criança recebe a autenticação de que é aquilo que vê pelo espelho e assume um eu equivalente ao objeto de desejo da mãe, sem conseguir acessar esse desejo como um significante. O Outro como lugar onde se situa a cadeia significante (Lacan, 1964/2008) não é acessível ao sujeito em encaminhamento psicótico.

De acordo com Soler (2002/2007), o agente materno só se torna o significante do desejo materno se há a simbolização de sua ausência. Quando esse desejo não é simbolizado como significante, a operação da metáfora paterna, que colocaria o Nome-do-Pai em substituição ao desejo da mãe também estaria impedida, como demonstrado pela descrição do movimento 6 .

Quando não há a insinuação de um lugar exterior a que o Outro materno se dirige, isto é, quando não há ausência simbolizável, o gozo é assentido somente em torno do corpo da criança. Segundo Laznik (2016), haveria um excesso de investimento materno nesse momento, que 
caracterizaria um momento fálico exacerbado na retroação do movimento 3 . Diante da equivalência que os primeiros momentos da constituição trazem ao corpo do agente materno, Laznik (2016) pontua que seria observável um excesso de libidinização das crianças quando as mães não se dirigem contentes ao pai ou quando excitam demasiadamente seus filhos. É importante ressaltar que essa constatação clínica diz respeito a uma maneira de sujeição ao desejo materno que pode se colocar pelos mais diversos contextos. A maneira como o sujeito se posiciona diante do Outro é fruto de uma combinatória de fatores que se presentificam em seu processo constitutivo: há a necessidade da dimensão do corpo do agente materno, mas os elementos que o atravessam estão inclusos na assimilação do mundo de linguagem pela criança. Para Mannoni (1964/1985), a criança psicótica é parte de um sintoma parental. Assim, a transformação do discurso - que não se restringe à palavra do agente materno -, ao qual a criança está aprisionada, pode impulsioná-la a estabelecer-se como sujeito.

Seguindo com a trança, a partir do que Laznik (2016) apresenta, podemos pensar que, na psicose da criança, a ausência de uma referência simbólica da falta retroage aumentando as proporções que o Imaginário toma sobre o Real, fazendo do movimento 2 duplamente fracassado. Visto que o Imaginário não cumpre a função de contornar a falta, mas de preenchêla completamente, o movimento 3, enquanto a sobreposição do Simbólico sobre o Imaginário, também poderá estar comprometido.

\section{De uma possível falha preliminar do simbólico na psicose}

O movimento 3 no encaminhamento típico do sujeito se faz quando o Simbólico prevalece diante do Imaginário: “O falo é fundamental como significante, fundamental neste imaginário da mãe a quem trata de unir, já que o eu da criança repousa sobre a onipotência da mãe" (Lacan, 1956-1957/1995, p.197). O caráter insatisfatório que os objetos apresentados pelo agente materno possuem reverbera como frustração ao sujeito. Essa inconsistência da onipotência do agente materno insinua uma falta no Outro que o sujeito vai buscar preencher. A criança procura, nas voltas da demanda, o termo que a sustenta no lugar do Outro para se equivaler a ele, pois é o que pode fazer diante da própria falta (Vorcaro, 2004). O que supõe em falta no Outro é aquilo a que vai buscar corresponder. Desse modo, assume o estatuto simbólico de falo materno. Nas palavras de Lacan (1956-1957/1995, p. 230): “A criança se apresenta à mãe como lhe oferecendo o falo nela mesma, em graus e posições diversos". Diante do desejo materno insaciável, a criança se faz de objeto enganador. Nesse jogo pulsional, o sujeito encontra a discordância de si mesmo com o desejo materno, essa é a condição que o assegura como desejante (Vorcaro, 2004).

Freud, em Introdução ao Narcisismo (1914/2010, p. 25), insinua esse momento fundamental na constituição do sujeito quando escreve o lugar privilegiado em que os pais posicionam seus filhos nos primórdios da infância:

Os pais são levados a atribuir à criança todas as perfeições — que um observador neutro nelas não encontraria - e a ocultar e esquecer todos os defeitos [...]. His Majesty the Baby, como um dia pensamos de nós mesmos. Ela deve concretizar os sonhos não realizados de seus pais, tornar-se um grande homem ou herói no lugar do pai, desposar um príncipe como tardia compensação para a mãe.

Para Laznik (2016), uma criança que vai bem rumo ao estatuto de sujeito barrado tem seu tempo de majestade transitório, pois, para a ordem simbólica ser retomada, a áurea imaginária 
que reveste a criança não pode perdurar. A destituição do lugar fálico da criança é o que caracteriza a passagem do Simbólico sobre o Imaginário.

Laznik (2016) compreende que na psicose infantil existiria uma incapacidade do agente materno de suspender o seu gozo sobre a criança, fazendo prevalecer a imaginarização do lugar fálico que ela ocupa. Nesse sentido, podemos pensar que, no sujeito que se encaminha para uma psicose, a grandeza do Imaginário é o que mantém a falta simbólica excluída. O Outro onipotente a quem o sujeito se submete mantém-se poderoso ao sempre saber sobre o sujeito criança, e, por não se remeter à falta, não exerce função de Outro simbólico. Fracassa o movimento 3. A correspondência imaginária que a criança faz ao objeto de desejo materno é sólida ao ponto de não precisar movimentar-se para obter reconhecimento, ela executa a presença de objeto do desejo materno, como Lacan (1969/2003b, p. 370 - itálicos nossos) demonstra:

A criança realiza a presença do que Jacques Lacan designa como objeto $a$ na fantasia. Ela satura, substituindo-se a esse objeto, a modalidade de falta em que se especifica o desejo (da mãe), seja qual for sua estrutura especial: neurótica, perversa ou psicótica. Ela aliena em si qualquer acesso possível com a sua própria verdade, dando-lhe corpo, existência e até a exigência de ser protegida.

Certa alienação imaginária se produz como necessária à constituição do sujeito - quase toda criança assume um lugar fálico no desejo parental. No caso da psicose infantil, ao realizar a presença do objeto de desejo materno demasiadamente, a criança termina por cristalizar-se como objeto $a$, ao invés de apreendê-lo como causa de desejo ou como ponto de encontro do sujeito com a falta simbólica que impulsionaria o funcionamento em cadeia significante:

Produz-se uma elisão que só pode ser notada a partir do objeto $a$, embora seja precisamente esse objeto que ela subtrai de qualquer apreensão exata. Digamos, pois, que ela só é compreendida ao se opor a que seja o corpo da criança que corresponda ao objeto $a$ - o que é delicado ali onde não se evidencia nenhuma pretensão semelhante, que só seria movida pela suspeita da existência do objeto $a$. Ela seria movida, justamente, por funcionar o objeto $a$ como inanimado, pois é como causa que ele aparece na fantasia (Lacan, 1969/2003a, p. 366).

Se o objeto criança preenche a falta do Outro materno, o objeto $a$ fica elidido, não emerge entre os significantes e será a própria criança - e não o falo - que funcionará como um significante. De acordo com Vorcaro (1999, p. 36):

A criança fica colada ao mandato que ela é o que falta no Outro. Encarnando essa falta, ela preenche o intervalo entre significantes na mesma função de qualquer significante: remetese a outro significante. Na solidez em que a cadeia significante primitiva é apanhada, a abertura dialética está impedida, e o significante representa outro significante num deslizamento infinito.

Nessa situação, se estabelece uma forçagem incessante de uma completude impossível, que traz angústia. Miller (1996/2014, p. 5) ressalta: "Quanto mais a criança preenche a mãe, mais ela angustia, de acordo com a fórmula segundo a qual é a falta da falta que angustia". Por não conseguir se separar do imaginário materno, continua impossibilitada de se deparar com o desejo materno enquanto um significante.

Mannoni (1964/1985, p. 42) constata que, para quem realiza a função da mãe, já existe uma espécie de "evocação alucinatória" de alguma coisa de sua própria infância que supõe a esse futuro filho. Isto é, desde o princípio, o filho é imaginado a partir das próprias vivências infantis do agente materno. Ao nascer, há uma primeira separação, pois o filho real não corresponde 
completamente ao imaginário materno. A partir daí o agente materno vai procurar meios de reestabelecer essa fantasia primordial, porque é a partir dela que o sujeito ocupa um lugar no seu próprio desejo. Desde esse momento, a relação agente materno e filho vai ser atravessada por um mal-entendido entre a idealização materna e a presença do neonato. A autora demonstra que o filho é destinado a preencher a falta materna, pois essa é a condição de sua existência no mundo. De certo modo, Mannoni (1964/1985) explica que nos casos em que há uma problemática psíquica colocada, como na psicose infantil, esse chamado materno pode estar configurado como uma convocação, na qual a dimensão do desencontro entre imaginário materno e filho real está impedida de se colocar: "Todo desejo de despertar, por parte do filho, vai ser sistematicamente combatido pela mãe" (Mannoni, 1964/1985, p. 43).

De acordo com Lacan (1970/1992 p. 105), o desejo materno é um significante que impulsiona o sujeito na linguagem e marca sua relação com ela para sempre: "O papel da mãe é o desejo da mãe. É capital. O desejo da mãe não é algo que se possa suportar assim, que lhes seja indiferente. Carreia sempre estragos. Um grande crocodilo em cuja boca vocês estão - a mãe é isso. Não se sabe o que lhe pode dar na telha, de estalo fechar sua bocarra. O desejo da mãe é isso". O psicanalista traz a dimensão de que aquilo que está em jogo na constituição do sujeito não é a mãe como tal, mas o desejo da mãe, pois é ele que convoca a criança ao mundo da linguagem. O que demonstra metaforicamente com o "fechamento da bocarra do crocodilo" é a possibilidade de que o desejo da mãe como significante se torne o próprio sujeito, como ocorre nas psicoses. Isso quer dizer que a dimensão insaciável do desejo materno precisa se manter. Desse modo, a alocação da criança como objeto que falta à mãe, ou seja, metáfora do falo materno, só é bem sucedida se fracassar. Se o sujeito se fixa à identificação fálica, obstrui o caminho da significação fálica e da castração simbólica. Nesse sentido, o caráter insaciável do desejo da mãe é paradoxal. Ao mesmo tempo em que faz a insistência de convocar o sujeito, pode aniquilá-lo se não se mantém como insaciável. A questão é que essa insaciabilidade precisa tomar forma pela simbolização da falta, senão o sujeito permanecerá restrito às exigências do gozo materno. Miller (1996/2014, p. 2) descreve que a "mãe só é suficientemente boa se não o é em demasia, se os cuidados que ela realiza não a desviam de desejar como mulher". A função da mãe é desejar, mas o que assegura a criança como sujeito desejante é o investimento desse agente materno em outros objetos que não a criança. A criança deve ao mesmo tempo preencher - fazer-se de falo materno - e dividir: manter o agente materno desejante.

Nessa perspectiva, entende-se que a maneira como a criança psicótica incorpora o objeto de desejo materno se relaciona com a sua impossibilidade de conceber o agente materno como sujeito dividido, que ela somente preenche. Esse comprometimento da dimensão do desejo nas crianças psicóticas permite supor que, para o sujeito desejante advir, é imprescindível que o desejo do agente materno se assegure por um objeto que não seja o filho. De outro modo: o desejo materno deve estar mais além da mãe, não deve se reduzir à função materna.

\section{Considerações finais}

Entendemos que o fracasso da movimentação 2 representa que o pequeno sujeito psicótico permanece identificado à situação de primeira alienação: em que tudo que é do sujeito está no campo do Outro (Lacan, 1964/2008). A operação de separação, definida por Lacan (1964/2008) como o recobrimento de duas faltas, não pode se efetuar, pois o sujeito psicótico não consegue se deparar com o espaço entre os significantes. Isso se desdobra de forma que o sujeito psicótico 
é impedido de se apropriar dos significantes que podem representá-lo. Em seguida, o movimento 3 também se comprometerá, pois o excesso de alienação simbólica produz também um excesso de alienação imaginária.

Para Laznik (2016), a configuração do nó borromeano que tem seus movimentos 2, 3 e 6 falhos implica a desarticulação da instância Simbólica, isto é: o referente simbólico se coloca fora do alcance de um sujeito que está em vias psicóticas. O que é determinante na desarticulação da dimensão Simbólica é a falha no movimento 6, representando a ausência da castração simbólica, que retroage sobre as outras movimentações. Nesse sentido, há algo de fundamental que se presentifica nas psicoses da criança e que marca a especificidade desse quadro clínico: a aderência exacerbada ao discurso materno e a ausência de simbolização da falta.

Ao verificarmos que o movimento 6 é a atualização do movimento 3, constatamos a necessidade do significante de passar por sucessivas confirmações para se inscrever, até o momento da adolescência em que o sujeito é convocado a assumir a responsabilidade por suas próprias palavras e pela sua própria sexualidade, ou seja, é colocado à prova (Bernardino, 2004). Cabe acrescentar que Lacan, no final do Seminário RSI (1974-1975), considera a hipótese de que todo sujeito passa por dificuldades em sua própria constituição, de forma que nenhum nó borromeano é perfeitamente enodado em três elos, havendo sempre a necessidade de uma quarta amarração que permita uma organização discursiva que o faça circular na cadeia significante. Capanema e Vorcaro (2017) constatam que, "na trança ou no nó de três ou quatro elos, a condição borromeana permanece sendo suposta como necessária para a constituição do sujeito, mas suas falhas só serão distinguíveis após o sujeito ter reparado seus lapsos com o quarto elo" (p. 392). No caso das psicopatologias graves da infância, estariam em jogo fracassos mais complexos que comprometem a própria constituição subjetiva - como nos casos em que um dos elos pode se soltar dos demais. De acordo com Vorcaro (2004), a relevância dessa topologia no tratamento de psicopatologias graves deve-se à possibilidade de se formalizar os acidentes que algo de não efetuado representa. Considerando que o percurso de constituição do sujeito é um texto que a criança pode produzir na transferência com o psicanalista, esta topologia do nó borromeano funciona como uma importante ferramenta de leitura clínica não apenas da psicose infantil, mas de todas as problemáticas que podem ocorrer no tempo da infância.

Assim, entendemos que, mais do que identificar sinais, importa compreender a relação em que a criança está inscrita no desejo materno. Desejo este atravessado pelo Nome-do-Pai, que também não se restringe à figura paterna, mas se refere aos significantes que permeiam a cultura em determinada época. Isso nos leva a pensar que a diminuição dos casos de psicose infantil, também na clínica psicanalítica, pode estar relacionada a uma mudança na forma como se pensa a maternidade atualmente e o que é exigido de uma mulher em nossa sociedade. Isso também nos permite questionar o aumento do diagnóstico de autismo como produto de uma época em que o discurso do Outro não pode mais servir de referência. Afinal, na lógica capitalista do consumo, é o objeto que muitas vezes orienta a cadeia significante. Assim, ainda que a topologia nos permita situar uma diferenciação clínica e teórica entre autismo e psicose infantil, a hipótese de uma quarta estrutura na infância - se levarmos em conta que aquilo que orienta uma estrutura é o Nome-do-Pai - parece-nos insuficiente para sustentar uma psicopatologia da infância. No caso das psicoses em adultos, o modelo estrutural foi repensado pelo próprio Lacan (1975-76/2007) em seu seminário sobre Joyce, no qual a temática do quarto elo continua a ser desenvolvida. Laznik (2016) se propõe a tratar do nó de Joyce como um protótipo do nó do 
autismo, pois, tanto no caso de Joyce, em que os movimentos comprometidos seriam 3, 4 e 5, quanto no caso do autismo, em que os movimentos comprometidos seriam 1, 2 e 5, estaria em jogo a desvinculação da instância Imaginária do nó. Mas essa semelhança não implica que Joyce seja diagnosticado como autista. O caráter retroativo, interdependente e maleável da trançagem do nó borromeano permite considerar que, ainda que as dificuldades na constituição do sujeito comprometam uma mesma instância do nó, isso não significa que estará em jogo uma mesma psicopatologia e nem que ela irá persistir na vida adulta. Como vimos, diferentemente do caso de Joyce e do autismo, é o registro Simbólico que se desvincula das outras instâncias quando a criança se encontra em vias psicóticas. E, justamente por considerarmos outras formas de incidência do Nome-do-Pai, que não se restringem ao pai edípico (Capanema e Vorcaro, 2017), concordamos com Bernardino (2004) quando esta afirma que, na infância, temos "psicoses não decididas", assim como "autismos não decididos".

\section{Referências}

American Psychological Association - APA (2002). DSM-IV-TR: Manual Diagnóstico e Estatístico de Transtornos Mentais. (4a ed.) Porto Alegre, RS: Artmed.

American Psychological Association - APA (2014). DSM-V-TR: Manual Diagnóstico e Estatístico de Transtornos Mentais. (5a ed.) Porto Alegre, RS: Artmed.

Bernardino, L-F. (2004). As psicoses não decididas da infância: um estudo psicanalítico. São Paulo, SP: Casa do Psicólogo.

Bernardino, L-F. (2010, abr./mai.). Mais além do autismo: A psicose infantil e seu não lugar na atual nosografia psiquiátrica. Psicologia Argumento, 28(61), 111-119. Disponível em: https://periodicos.pucpr.br/index.php/psicologiaargumento/article/view/19617/18961

Calligaris, C. (2013). Introdução a uma clínica diferencial das psicoses. (2a ed.) Porto Alegre: Artes médicas. (Trabalho original publicado em 1989).

Capanema, C, Vorcaro, A (2017). A condição do ser falante no nó borromeano. Estilos da clínica, 22 (2), 388-405. Doi: https://doi.org/10.11606/issn.1981-1624.v22i2p388-405

Freud, S. Introdução ao narcisismo. (2010). In Freud, S. Obras Completas de Sigmund Freud (P.C. de Souza, trad., Vol. 12, pp. 9-37). São Paulo: Cia. das Letras. (Trabalho original publicado em 1914).

Lacan, J. (1955-1956). Le séminaire, livre III: psychoses. (Versão de uso interno da Associação Lacaniana Internacional).

Lacan, J. (1974-1975). Le séminaire, livre XXII: RSI. Inédito.

Lacan, J. (1988). O seminário, livro 11: Os quatro conceitos fundamentais da psicanálise. (2a ed., M.D. Magno, trad.) Rio de Janeiro: Jorge Zahar. (Apresentação oral em 1964, original publicado em 1973).

Lacan, J. (1988) O seminário, livro 3: As psicoses. (2a ed. revista., A. Menezes, trad.) Rio de Janeiro: Jorge Zahar. (Apresentação oral em 1955-1956, original publicado em 1981).

Lacan, J. (1992). O Seminário, livro 17: o avesso da psicanálise. (A. Roitman, versão brasileira) Rio de Janeiro: Jorge Zahar. 
Lacan, J. (1995). O seminário, livro 4: a relação de objeto (D. D. Estrada, trad.). Rio de Janeiro: Jorge Zahar. (Apresentação oral em 1956-57, original publicado em 1994).

Lacan, J. (1998). Posição do Inconsciente. In J. Lacan, Escritos. (V. Ribeiro, trad.) Rio de Janeiro, RJ: Jorge Zahar. (Apresentação oral em 1960, original publicado em 1966). pp. 829864.

Lacan, J. (2003a). Alocução sobre as psicoses da criança. In J. Lacan, Outros escritos. (V. Ribeiro trad., pp. 359-368) Rio de Janeiro: Jorge Zahar. (Apresentação oral em 1969, original publicado em 2001).

Lacan, J. (2003b). Nota sobre a criança. In J. Lacan, Outros escritos. (V. Ribeiro trad., pp. 369370) Rio de Janeiro: Jorge Zahar. (Apresentação oral em 1969, original publicado em 2001).

Lacan, J. (2007). O seminário, livro 23: o sinthoma. (S. Laia trad.) Rio de Janeiro: Jorge Zahar. (Apresentação oral em 1975-1976, original publicado em 2005).

Laznik, M.-C. (2016). Podemos pensar uma clínica do nó borromeo que diferencie psicose e o autismo nos bebês? In M.-C Laznik, M.-C., C. Bursztejn, \& B. Touati, Distinção clínica e teórica entre autismo e psicose na infância (pp. 27-55). São Paulo: Instituto Langage.

Mannoni, M. (1985) A relação fantasmática do filho com sua mãe. (M. R. Duarte trad.) In Mannoni, M. A criança retardada e a mãe. (pp. 37-44). São Paulo, SP: Martins Fontes. (Trabalho original publicado em 1964).

Miller, J.-A. (2014). A criança entre a mulher e a mãe. Opção Lacaniana online, 5(15). (Trabalho original publicado em 1996). Disponível em http://www.opcaolacaniana.com.br/pdf/numero 15/crianca entre mulher_mae.pdf

Soler, C. (2007) O inconsciente a céu aberto da psicose. (V. Ribeiro trad.) Rio de Janeiro: Jorge Zahar. (Trabalho original publicado em 2002).

Vanoli, E-N, \& Bernardino, L-F. (2008). Psicose infantil: uma reflexão sobre a relevância da intervenção psicanalítica. Estilos da clínica, 13(25), 250-267. https://doi.org/10.11606/issn.1981-1624.v13i25p250-267.

Vorcaro, A. (1999). Da holófrase e seus destinos. In Vorcaro, A. Crianças na psicanálise: clínica, instituição, laço social (pp. 19-58). Rio de Janeiro, RJ: Companhia de Freud.

Vorcaro, A. (2004). A criança na clínica psicanalítica. São Paulo, SP: Companhia de Freud.

Revisão gramatical: Lucas Mello Carvalho Ribeiro

E-mail: lucasmcr@yahoo.com.br

Recebido em outubro de 2020 - Aceito em outubro de 2021. 